\title{
BIBLIOTECÁRIO E ARQUIVISTA: CONTRIBUIÇÕES ESTRATÉGICAS NAS ORGANIZAÇÕES
}

\author{
BIBLIOTECARIO Y ARCHIVERO: \\ CONTRIBUCIONES ESTRATÉGICAS \\ ENLASORGANIZACIONES
}

\author{
Márcio da Silva Finamor* \\ Claudio Paixão Anastácio de Paula**
}

\section{RESUMO:}

Introdução: Essa pesquisa apresenta uma reflexão teórica sobre os processos de atuação e atividades dos profissionais da informação: bibliotecário e arquivista. Estabelece um breve panorama de suas atividades, consideradas estratégicas na literatura da área.

Objetivo:Apresentar as perspectivas e possíveis contribuições do bibliotecário e arquivista para o desenvolvimento e aplicação de atividades estratégicas da informação em organizações.

Metodologia:Revisão de literatura sobre o profissional bibliotecário e arquivista, suas funções e atividades nas organizações. Um estudo teórico fundamentado em autores da Ciência da Informação.

Resultados:As ações realizadas pelos bibliotecários e arquivistas maximizam e promovem o uso da informação. Com os conceitos e técnicas fundamentais da área, como coleta e tratamento de documentos e informações, reaplica em um contexto renovado e de forma valorada.Os processamentos técnicos desse profissional são mais estratégicos do que qualquer atividade de gestão e necessários em qualquer ambiente. O profissional - arquivista - exerce maior atividade estratégica que qualquer um outro profissional da informação.

Conclusões:Conclui que o bibliotecário e arquivista possuem em seu perfil, formação, habilidades, atividades técnicas (tradicionais), teóricas, de gestão e de cunho estratégico para a organização. Suas atividades e contribuições são mais que estratégicas, são também sociais. Suas perspectivas e possíveis contribuições são promissoras e relevantes. Como também favorecem o apoio em tomadas de decisão, na criação de novos conhecimentos e no tratamento da informação com qualidade. Possuem um papel diferenciado nos processos de Gestão da Informação (GI), Gestão

*Mestrando em Ciência da Informação pelo IBICT/UFRJ. Especialista em Gestão Estratégica da Informação pela UFMG/ECI. Bibliotecário e Documentalista pela UFF. E-mail: marciofinamor@gmail.com.

**Doutor em Psicologia Social pela Universidade de São Paulo, Brasil. Professor da Universidade Federal de Minas Gerais, Escola de Ciência da Informação. E-mail: claudiopap@hotmail.com. 
do Conhecimento (GC), Gestão de Documental (GD) e de Inteligência Competitiva (IC), pois tradicionalmente, lida com a informação de forma técnica e teórica.

Palavras-chave: Bibliotecário. Arquivista. Atuação. Estratégia. Organização.

\section{INTRODUÇÃO}

O presente trabalhotem como intuito traçar o perfil de atividades dos bibliotecários e arquivistas nas organizações. E, por conseguinte, apontar novas possibilidades de atuação e contribuição desses profissionais nos ambientes onde estejam inseridos. Introduzindo uma reflexão sobre as atividades do profissional bibliotecário e arquivista nas empresas isto é, em atividades diferentes das tradicionais: bibliotecas e arquivos.

Nessas circunstâncias, podemos inferir que o fenômeno da globalização ampliou e modificou as redes de relacionamentos e do paradigma produtivo entre os indivíduos e os serviços informacionais. As transformações proporcionadas por sua expansão atingiram vários setores, dentre eles as organizações e empresas ${ }^{1}$.

Com isso, nos novos requisitos e atuais exigências da sociedade e das organizações na Era da informação e conhecimento ${ }^{2}$, tornou-se urgente a necessidade da empresa tratar e organizar a quantidade de informação disponível ao seu redor, bem como aperfeiçoar os modos de utilizá-la, pois a informação pode assumir caráter estratégico nesses ambientes, sendo matériaprima para a vantagem competitiva e para a geração de conhecimento. Desse modo, as organizações podem passar a diferenciar-se e destacar-se no mercado.

\footnotetext{
${ }^{1}$ Nesse trabalho, optamos intercambiadamente pela utilização das expressões organização e empresas. Elas serão utilizadas como equivalentes. Justifica-se essa escolha, embora os termos possam ser aplicados a conceitos diferentes, pelo fato da atuação dos profissionais de informação em qualquer um desses ambientes ter como papel atividades relevantes e estratégicas.

${ }^{2}$ Lastres e Albagli (1999, p. 8) referem-se à "era da informação e conhecimento" como a conjunção e a sinergia de uma série de inovações sociais, institucionais, tecnológicas, organizacionais, econômicas e políticas, isto é, a partir das quais a informação e o conhecimento passaram a desempenhar um novo e estratégico papel na sociedade e nas organizações.
} 
A informação tornou-se, portanto, o pilar principal de sustentação das organizações, ou seja, o reconhecimento de uma administração da informação e a racionalização do uso da informação são, naturalmente, estratégias e ações de crucial importância. Marchiori (2002) afirma que o reconhecimento das habilidades de criação, busca, armazenamento, acesso, análise e interpretação da informação são essenciais para indivíduos e grupos, sendo um fator crucial para os processos de tomada de decisão e de criação de estratégias dentro da organização, entre outros.

Como bem colocam alguns autores da área de Ciência da Informação, como Cianconi (1991), Marchiori (1996), Tarapanoff (2001), Valentim (2008) e outros, para que as organizações se mantenham de forma sustentável, é primordial que nelas haja tratamento e organização adequada da informação a fim de transformá-las em relevantes, precisas, consistentes e de fácil acesso.

No entanto, sem profissionais qualificados para administrar esses processos de organização da informação, as ações empreendidas nesse sentido tornam-se dispersas e, consequentemente, as organizações são afetadas.A chamada desses profissionais à ação possibilitaria incentivar e facilitar o uso das informações para a criação de estratégias através da informação de maneira colaborativa.

Dentro desse contexto, é onde o bibliotecário e arquivista têm seu espaço de atuação no ambiente organizacional, exercem um relevante papel ao trabalharem com as informações e com o conhecimento intelectual da organização, passando a agregar valor estratégico a estas. Afinal, a informação é um fator essencial para as organizações e indivíduos, tanto para o crescimento organizacional quanto para a evolução do ser humano e para a criação de novos conhecimentos. Destarte, consideramos que o profissional bibliotecário e arquivista é quem, tradicionalmente, em sua formação,lida com a informação e os documentos de forma técnica: de organização, recuperação e de busca, etc.

Neste sentido, esse trabalho procura contribuir para o desenvolvimento de ações estratégicas dos bibliotecários e arquivistas em apoio às organizações; a saber, como esses profissionais, a partir do uso das tecnologias e outros instrumentos (técnicos) e processos (de gestão), podem 
pensar e atuar em procedimentos estratégicos para o uso da informação e do conhecimento.

Como metodologia, foi feita uma revisão de literatura sobre o profissional bibliotecário e arquivista, suas funções e atividades nas organizações.É proposto, portanto, um estudo teórico fundamentado em autores da Ciência da Informação, Administração e áreas afins.

\section{A INFORMAÇÃO COMO FERRAMENTA DE TRABALHO}

Habituados com os processos de informação, bibliotecários e arquivistasatuam no tratamento, na mediação e comunicação das informações, inclusos nesses processos. Que de acordo com Cunha e Cavalcanti (2008, p. 294), é o "processo decomunicação que conduz a um conhecimento mais preciso". Na atualidade, estes promovem o uso da informação para gerar novos conhecimentos.

Esses profissionais, ao lidar com a informação e documentos podem subsidiar a criação de novos conhecimentos, de estratégias para o uso da informação, de novos modelos de disseminação da informação e na criação de novos serviços. Isto é, independente do seu formato e meio de comunicação, ela tem alguns propósitos. Um deles é poder exercer funções estratégicas dentro das organizações, dentre os processos de "gestão" e "técnicos". Pois, independentemente do tipo, formato ou suporte em que a informação esteja como documentos, livros, imagens, entre outros -, ela sempre poderá ser uma ferramenta que contribuirá para o aprimoramento do conhecimento, do aprendizado e da memória ${ }^{3}$.

Dentre essas atividades, Sales (2011, p. 60), revisitando Buckland (1991) retrata no que tange à denotação do ente informativo, compreende a informação como "coisa", "processo" e "conhecimento". Para o autor, a informação como processo reside no ato de informar, no qual o conhecimento

\footnotetext{
3"A memória faz parte do imaginário partilhado entre indivíduos e coletivos que na dinâmica do tempo produz, enuncia e significa o que chamaremos de informação. Grosso modo, o que queremos dizer é que, sem memória, sem a capacidade da lembrança, do resgate de uma dada experiência, imagem ou símbolo, não é possível reconhecer absolutamente nada no presente, tampouco realizar quaisquer ações" (PIMENTA, 2013, p. 151-152).
} 
transmitido por alguém é, de alguma forma, modificado. Diz respeito também ao que é perceptível, cognoscível; nesse sentido, a informação reduz a incerteza do sujeito que a recebe. Sales comenta que o ato de informar alguém e o fato dessa informação reduzir a incerteza de quem é informado pressupõe que "algo" informativo seja expresso, descrito ou representado. Esse "algo" informativo, que de forma tangível evidencia uma informação, denominada como coisa (dados, documentos, etc.). É essa informação que, no âmbito do tratamento (organização) da informação, é passível de ser processada, ou seja, trabalhada concretamente em um sistema de informação. Informação como coisa é a informação materializada.

Neste caminho, Capurro e Hjorland (2007, p. 187-188) elaboram a seguinte definição parainformação:

[...] Informação é qualquer coisa que é de importância na resposta a uma questão. Qualquer coisa pode ser informação. $\mathrm{Na}$ prática, contudo, informação deve ser definida em relação às necessidades dos grupos-alvo servidos pelos especialistas em informação, não de modo universal ou individualista, mas, em vez disso, de modo coletivo ou particular. Informação é o que pode responder questões importantes relacionadas às atividades do grupo-alvo. A geração, coleta, organização, interpretação, armazenamento, recuperação, disseminação e transformação da informação deve, portanto, ser baseada em visões/ teorias sobre problemas, questões, objetivos que a informação deverá satisfazer.

A informação e o conhecimento estão, direta ou indiretamente, ligados a quase todos os processos organizacionais. Pode-se afirmar, inclusive, que são fatores estratégicos ao desenvolvimento organizacional. Sobre esse aspecto, Choo (2003, p. 27) explica:

A informação é um componente intrínseco de quase tudo que uma organização faz. Sem uma compreensão dos processos organizacionais pelos quais a informação se transforma em percepção, conhecimento e ação, as empresas não são capazes de perceber a importância de suas fontes e tecnologias de informação. 
Para isso, como os profissionais em questão podem fazer essa investigação ${ }^{4}$ ?uais instrumentos usar? Existem processamentos técnicos eficazes para evitar problemas na estruturação e comunicação da informação, visto que, na atualidade, o problema não é mais a falta de informação, mas o seu excesso e o uso da informação.

2.1 Processamentos técnicos: uma vantagem estratégica

A informação, para ser estratégica, depende de vários fatores. Um desses elementos está em seu processo de organização, isto é, como ela foi processada, registrada, estruturada e representada para fins de acesso e recuperação.

A formação do bibliotecário e do arquivista incorpora técnicas e procedimentos da Biblioteconomia e da Arquivologia, mas acrescenta aos mesmos os imperativos do trato/análise da informação (muito mais mutantes e sujeitos a localismos que a organização de documentos de um acervo físico) e a compreensão tanto de sua origem (por que e de que modo se produzem, registram e divulgam informações) conforme apontam Smith e Barreto (2002, p. 22, grifo nosso).

Aqui, é oportuno salientar, que, embora ainda não haja consenso sobre todas as profissões que poderiam ser incluídas na designação "profissionais da informação", poderíamos dizer que, no Brasil, bibliotecários, arquivistas e os mestres e doutores em Ciência da Informação, jornalistas, analistas de sistemas, entre outros, formam, segundo Mueller (2004, p. 43), o núcleo desse grupo.

Sendo assim, os profissionais da informação destacados nesse trabalho têm em sua formação habilidades técnicas e teóricas, o que venha a ser 0 processo de organização da informação e do conhecimento, exercendo grande

\footnotetext{
${ }^{4}$ Investigação: no sentido, de como empreender ações com o intuito de conhecer os processos organizacionais em sua completude para identificar o lugar onde a informação é imprescindível e oferecer elementos para o bom uso dela.
} 
influência sobre ambos. Logo, o seu trabalho (técnico, teórico e mediador) ${ }^{5}$ com a informação passa a ser um grande diferencial, como o tratamento adequado das informações; dentro de uma estrutura adequada para o suporte que será inserido; e na melhor forma de transmissão.

Em todos esses processos e trabalho técnicos (tratamento e análise da informação e documentos)os bibliotecários e arquivistas, onde quer que estejam inseridos, têm a vantagem intelectual de serem os conhecedores da essência dos processos de análise e tratamento da informação e do conhecimento registrado (SANTOS, 2002, p. 108).

Dessa forma, esses profissionais podem exercer grande influência sobre as informações e conhecimento, tornando-os relevantes, de qualidade, de fácil acesso e entendimento para o seu uso e de tomadas de decisões nas organizações.

Nesse espaço de atuação, existe a relação dos tipos de domínios e de informações de responsabilidade exclusiva de arquivistas e bibliotecários, sobretudo no que diz respeito aos processos, instrumentos e produtos específicos à organização do conhecimento e da informação.

O quadro abaixo ilustra a configuração de como se pode compreender de maneira abrangente a representação dos domínios dentro da prática profissional nesses dois campos:

Quadro 1 - Representação de domínios na prática biblioteconômica e arquivística

\begin{tabular}{|c|c|c|}
\hline & Biblioteconomia & Arquivologia \\
\hline Domínios & $\begin{array}{c}\text { Relacionados aos campos de } \\
\text { assuntos, (comunidades } \\
\text { discursivas) }\end{array}$ & $\begin{array}{c}\text { Relacionados às entidades e órgãos } \\
\text { custodiadores (comunidades } \\
\text { discursivas) }\end{array}$ \\
\hline $\begin{array}{c}\text { Tipo de } \\
\text { Informação } \\
\text { (materializada, } \\
\text { institucionalizada } \\
\text { e socializada) }\end{array}$ & $\begin{array}{l}\text { Documentos de conteúdos } \\
\text { variados e com objetivos culturais } \\
\text { técnicos, científicos entre outros }\end{array}$ & $\begin{array}{c}\text { Documentos orgânicos, com objetivos } \\
\text { administrativos, além de culturais e de } \\
\text { pesquisa histórica }\end{array}$ \\
\hline
\end{tabular}

${ }^{5}$ Aqui não pretendemos expor e nem aprofundar teoricamente todas as técnicas e metodologias para a organização da informação e do conhecimento, e sim chamar a atenção das empresas e organizações para as habilidades técnicas e teóricas desses profissionais, que podem ser uma vantagem em relação ao mercado competitivo. 
Márcio da Silva Finamor, Claudio Paixão Anastácio de Paula

Bibliotecário e arquivista: contribuições estratégicas nas organizações

\begin{tabular}{|c|c|c|}
\hline $\begin{array}{l}\text { Processos } \\
\text { (organização da } \\
\text { informação) }\end{array}$ & $\begin{array}{l}\text { Catalogação; Classificação; } \\
\text { Indexação; } \\
\text { Condensação }\end{array}$ & $\begin{array}{c}\text { Descrição Arquivística; Classificação } \\
\text { Arquivística }\end{array}$ \\
\hline $\begin{array}{l}\text { Instrumentos } \\
\text { (organização do } \\
\text { conhecimento) }\end{array}$ & $\begin{array}{l}\text { Sistemas de Classificação; Lista } \\
\text { de cabeçalhos de assunto; } \\
\text { Taxonomia; Tesauros; Ontologias }\end{array}$ & Classificações \\
\hline $\begin{array}{l}\text { Produtos } \\
\text { gerados }\end{array}$ & $\begin{array}{c}\text { Notações classificatórias; } \\
\text { Cabeçalhos de assunto; Índices; } \\
\text { Resumos }\end{array}$ & $\begin{array}{c}\text { Guias; Inventários; Catálogos; Índices; } \\
\text { Tabelas de equivalência; Estruturas } \\
\text { classificatórias }\end{array}$ \\
\hline
\end{tabular}

Fonte: Sales (2011, p. 62-63).

Os domínios trabalhados pela Biblioteconomia e pela Arquivística se distinguem quanto ao enfoque e se oficializam em documentos de natureza e objetivos distintos. As práticas profissionais em ambos os contextos pressupõem uma informação passível de manuseio técnico (informação materializada) inserida em uma organização significativa (informação institucionalizada e socializada) para fins de recuperação e uso (SALES, 2011, p. 63). A partir desse quadro, sobre cada profissional e seus domínios, concluise que ambos trabalham com a informação materializada, no entanto, de natureza distinta em relação aos processos e instrumentos.

\section{BIBLIOTECÁRIO E ARQUIVISTA}

As habilidades técnicas do bibliotecário são fundamentais para organização da informação, seja ela física ou virtual, em bibliotecas (tradicional) ou empresas. Os processos de catalogação, classificação, indexação, linguagem documentária, análise de informação, entre outros, são apenas mais uma parte de todo um processo principal.

Nessa perspectiva, Silva (2005, p. 53), reforça que "[...] o processamento técnico deve exercer as suas atividades sempre buscando transcender a execução de atividades puramente técnicas. Tratar informação é muito mais que catalogar, classificar e indexar [...]". Essas são apenas atividades que fazem parte de um objetivo maior: possibilitar acesso dos usuários/clientes a uma informação da qual necessita, seja ela técnica, científica, cultural, etc. 0 
que importa é pensar que essas atividades irão possibilitar o desenvolvimento informacional de uma pessoa e, na tentativa de proporcionar-Ihe a construção de um pensamento mais crítico que a fará entender e questionar sua realidade. Esse estímulo cognitivo leva ao aperfeiçoamento de estratégias e inovações, e isso é essencial nas organizações.

Já o profissional arquivista seja nas Instituições/organizações sejam elas públicas ou privadas torna-se necessário e relevante o processo de organização das informações registradas (documentos) como também, a rapidez de seu acesso e recuperação.

Como por exemplo, o tratamento da informação digital para o acesso e preservação, envolve aspectos legais, técnicos e administrativos, para isso, é necessário que as instituições disponham de profissionais de várias áreas para o tratamento desse tipo de informação, especialmente o arquivista(GRÁCIO, FADEL, 2010, p. 71).

Segundo Santos (2011, p. 149), todos os membros de uma organização necessitam de (informação e documentos) para realizar suas respectivas funções e buscam essas informações no interior e no exterior da organização.

Souza (2011, p. 112-119) ao discorrer sobre a imagem profissionalarquivista, no âmbito da história daprofissão, das suas atribuições, da sua formação, e do mundo do trabalho. Reitera uma reflexão da pesquisadora e diretora da Escola Alemã de Arquivo Angelika Menne-Haritz, e considera que: os arquivistas possuem e desenvolvem métodos necessários para ascender às provas contidas nos documentos administrativos. E que, não há nenhuma outra profissão que tenha métodos similares e está é precisamente a razão pela qual os arquivistas são especialistas indispensáveis em qualquer ambiente.

\section{BIBLIOTECÁRIOS E ARQUIVISTAS EM ATIVIDADES DE GESTÃO}

O profissional bibliotecário e arquivista, em suas atividades e competências adquiridas, assume ocupações que se enquadram entre a fase tecnicista e humanista, núcleo válido de sua formação e da sua atividade profissional. 
Além disso, nos próprios ambientes tradicionais são nítidas as mudanças, como a presença da internet e da automação, a utilização mais intensa de recursos eletrônicos, como a evolução das bases de dados e das mídias sociais, além da incorporação de novas tarefas e a oferta de diferentes produtos e serviços - foco na gestão.

Importante mencionar, que os processamentos técnicos antecedem aos procedimentos metodológicos relacionados à gestão. Em outras palavras, sem os processamentos técnicos e teóricos de organização da informação e conhecimento, as práticas de gestão serão dispersas e frustrantes para a organização.

\subsubsection{Bibliotecário na Gestão da Informação (GI)}

A informação e o uso que fazemos dela são os fatores principais para o atendimento das necessidades individuais como também organizacionais. É necessário, então, ter meios adequados (pessoas e tecnologia) para tratar, preservar, comunicar, disseminar e estabelecer normas e acesso à informação, visando sua efetiva utilização.Um dos processos e meios que facilitam o uso da informação é a Gestão da Informação (Gl).

Compreende-se aqui $\mathrm{Gl}$ em ambientes organizacionais como um conjunto de atividades que visa: obter um diagnóstico das necessidades informacionais; mapear os fluxos formais de informação nos vários setores da organização; prospectar, coletar, filtrar, monitorar, disseminar informações de diferentes naturezas; elaborar serviços e produtos informacionais; organizar a informação ("construir taxonomias, tesauros, tabelas de temporalidade, indexar, classificar, definir prazos de guarda e descarte, elaborar bases de dados, páginas web'), objetivando apoiar o desenvolvimento das atividades/tarefas cotidianas e o processo decisório nesses ambientes (VALENTIM, 2008, p. 4).

É nesse momento que o bibliotecário se destaca como elemento essencial nos processos de Gl nas organizações: realizando o mapeamento dos fluxos informacionais na empresa, para compreender quem produz e quem necessita das informações estratégicas; tratando adequadamente as informações provenientes desses fluxos informacionais; possibilitando 
recuperação e acesso rápidos às informações, subsidiando o planejamento estratégico e a tomada de decisão.E assim esse profissional mostra seu valor para a instituição e reaplica os conceitos fundamentais da área, como coleta e tratamento de documentos e informações, em um contexto renovado e de forma valorada.

\subsubsection{Bibliotecário na Gestão do Conhecimento (GC)}

No contexto organizacional, a GC pode ser entendida como um conjunto de atividades que visam trabalhar a cultura organizacional/informacional e a comunicação organizacional/informacional no intuito de proporcionar um ambiente favorável em relação à criação/geração, aquisição/apreensão, compartilhamento/socialização e uso/utilização de conhecimento (VALENTIM, 2008, p. 4).

Para Tonini e Sá (2012), o bibliotecário, devido aos seus conhecimentos de classificação e indexação, é essencial para prestar relevante serviço na tarefa de identificar especialistas numa organização. Baseado na informação sobre quem pesquisa temas específicos, pode contribuir de forma eficaz na implantação das comunidades de práticas e outras ações que envolvem a participação de profissionais que conheçam a organização, seus funcionários, suas atividades e os processos do negócio. O bibliotecário pode atuar como mediador entre as necessidades de conhecimento e as fontes disponíveis, muitas vezes fontes humanas que viabilizam a realização da ponte entre 0 explícito e o tácito e vice-versa.

\subsubsection{Bibliotecário na Inteligência Competitiva (IC)}

Segundo Pinheiro (2006, p. 30), as transformações contemporâneas atingiram o Brasil e a emergência da IC é decorrência de uma nova era, na qual a informação assume o papel central. Segundo Valentim e outros (2003), IC é: 
[...] o processo que investiga o ambiente onde a empresa está inserida, com o propósito de descobrir oportunidades e reduzir os riscos, bem como diagnostica o ambiente interno organizacional, visando o estabelecimento de estratégias de ação a curto, médio e longo prazo (VALENTIM et al, 2003).

Num processo sistemático, através de várias ações integradas e desenvolvidas, o bibliotecário pode atuar na etapa de prospecção e monitoramento, seleção e filtragem, das informações em variadas fontes informacionais, no tratamento e agregação de valor às informações, na disseminação e transferência no suporte mais adequado e na geração e no uso de dados, informação e conhecimento, isto é, todo ativo informacional e intelectual da organização (VALENTIM et al, 2003).

\subsubsection{Arquivista na Gestão de Documentos (GD)}

O profissional arquivista com o apoio da tecnologia, processos, e instrumentos ${ }^{6}$, teoria e técnica pode pensar em políticas e metodologias para evitar o acúmulo de documentos, entre outros. Um desses processos é a de Gestão de Documentos (GD).

A gestão documental é um processo administrativo que permite analisar e controlar sistematicamente, ao longo de seu ciclo de vida, a informação registrada que se cria, recebe, mantém e utiliza numa organização em correspondência com sua missão, objetivos e operações (PONJUÁN DANTE, 2004, p. 129).

\footnotetext{
${ }^{6}$ Alguns Instrumentos relevantes: plano de classificação, protocolo (tramitação, empréstimo, desarquivamento), manual de redação e controle de produção de formulários, tabela de temporalidade, comissão de avaliação, glossário, tesauros, guias de transferência e recolhimento, normas arquivística (classificação, avaliação, transferência, recolhimento, acesso, eliminação, preservação etc.), listagem e edital de eliminação, política de segurança da informação (prevenção contra desastres, contingências), sistema informatizado de gestão de documentos (SANTOS, 2013, p. 10).
}

Inf. Prof., Londrina, v. 5, n. 2, p. 228 - 245, jul./dez. 2016.

http:www.uel.br/revistas/infoprof/ 


\subsubsection{Análise da informação arquivística ${ }^{7}$}

Para isso, faz-se necessário também uma preparação dos recursos humanos, financeiros, tecnológicos e materiais. Todavia, estes profissionais os arquivistas - necessitam adotar uma consciência crítica com relação às novas exigências, apresentadas pelo mercado contemporâneo e globalizado, visando a sua habilitação para atividades que envolvem cada vez mais a intelectualidade.

$\mathrm{Na}$ Arquivologia é fundamental e indispensável que estes papéis citados sejam compreendidos a partir do interior das próprias entidades onde 0 arquivista atua como gestor da informação, seja esta tomada como instrumento da administração e do direito, ou como testemunho da história e do exercício da cidadania. Ele é um provedor da informação administrativa e jurídica. $O$ arquivista está suficientemente capacitado para elaborar instrumentos de pesquisa que dão acesso à informação, que sua formação lhe dá elementos que o habilitam a não permitir que se perca a essência da informação na montagem da representação descritiva (BELLOTTO, 2004, p. 5).

Moreno (2007, p. 19) afirma que em ambientes organizacionais as tomadas de decisões são baseadas em documentos, isto é, em informação registrada. A informação arquivística é indispensável, sendo utilizada e necessária como aporte ao processo de tomada de decisão. A importância do arquivista nas organizações é clara: é imprescindível sua atuação e atividades

\footnotetext{
${ }^{7}$ Conforme (SANTOS, 2011, p. 155), ao se analisar a "informação arquivística" como um dos objetos da Arquivística é preciso atentar-se para não incorrer em erro de análise sobre o entendimento desse conceito no que se refere a diferenciá-lo do documento arquivístico. "[...]Essas informações podem ser orgânicas, quando forem elaboradas, emitidas ou recebidas no âmbito da missão institucional e registradas num suporte [...]. [...] ou não orgânicas, quando não inseridas nas missões da instituição ou quando não registrada num suporte (informação verbal)" (SANTOS, 2011, p. 156-157). "[...] o registro das informações orgânicas demanda a produção de documentos arquivísticos que atendam aos requisitos funcionais relativos ao procedimento ao qual a informação está vinculada. Tal documento arquivístico, ao ser preservado para referências futuras, gera 0 arquivo da instituição. $O$ tratamento do documento arquivístico é uma consequência da necessidade de gerenciar a informação orgânica registrada, ou seja, a informação arquivística" (SANTOS, 2011, p. 160).
} 
dentro da organização, nos quesitos informação; documentos; em apoio a tomadas de decisão e cunho estratégico.

\section{CONSIDERAÇÕES FINAIS}

Através do levantamento teórico, ficou evidente que os profissionais bibliotecários e arquivistas, além de estarem aptos e possuírem competências para atuar em ambientes organizacionais, especialmente em atividades técnicas, teóricas e intelectuais: de gestão, estes profissionais estão tornandoas pertinentes e úteis para tomada de decisões e participando como insumo para a geração de conhecimento, inovações e principalmente no cunho estratégico.

Com base na literatura da Ciência da Informação e da Arquivologia, podemos afirmar que esse profissional - arquivista - exerce maior atividade estratégica que qualquer um outro profissional da informação. Pois, suas atividades estão relacionadas diretamente com os tomadores de decisão. E é com base em documentos registrados que as maiores decisões são tomadas nas organizações.

E que as perspectivas e possíveis contribuições do bibliotecário e arquivista em atividades estratégicas com o uso da informação e documentos em organizações são promissoras, relevantes e contribuem por colaborarem na organização da informação, do conhecimento, no estímulo do uso da informação e na criação de novos conhecimentos e no fazer inovar. Como também favorecem o apoio em tomadas de decisão, o planejamento estratégico e na inteligência competitiva. Sendo consideradas essas atividades como alto grau estratégico para a organização.

Suas atividades e contribuições são mais que estratégicas, são também sociais, pois esses profissionais, com seu conhecimento acadêmico e suas práticas profissionais, concebem transformações na Sociedade em que vivem, se compreendem suas estruturas e as mudanças que estão ocorrendo. Desde as atividades tradicionais para a incorporação de novas atividades/ambientes. 


\section{REFERÊNCIAS}

BELLOTTO, H. L. Arquivos permanentes: tratamento documental. 2. ed. São Paulo: TA Queiroz, 2004.

BUCKLAND, M. Information as thing. Journal of American Society of Information Science, v. 42, n.5, p. 351-360, 1991.

CAPURRO, R.; HJØRLAND, B. O conceito de informação. Perspectivas em Ciência da Informação, Belo Horizonte, v. 12, n. 1, p.148-207, jan./abr. 2007. Disponível em:

$<$ http://portaldeperiodicos.eci.ufmg.br/index.php/pci/article/viewFile/54/47>. Acesso em: 8 out. 2014.

CHOO, C. W. A organização do conhecimento: como as organizações usam a informação para criar significado, construir conhecimento e tomar decisões. São Paulo: Senac, 2003.

CIANCONI, R. de B. Gerencia da informação: mudança nos perfis profissionais. Ciência da Informação, Brasília, DF, v. 20, n. 2, p. 204-208, jul./dez.1991. Disponível em:

<http://revista.ibict.br/ciinf/index.php/ciinf/article/viewFile/1266/902>. Acesso em: 11 out. 2014.

CUNHA, M. B. da; CAVALCANTI, C. R. de O. Dicionário de Biblioteconomia e Arquivologia. Brasília, DF: Briquet de Lemos, 2008.

GRÁCIO, C. A; FADEL, B. Estratégias de preservação digital. In: VALENTIM, M. L. P (Org.). Gestão, mediação e uso da informação. São Paulo: Cultura Acadêmica, 2010.

LASTRES, M. M. H.; ALBAGLI, S. Informação e globalização na era do conhecimento. Rio de Janeiro: Campus, 1999.

MARCHIORI, P. Z. A ciência e a gestão da informação: compatibilidades no espaço profissional. Ciência da Informação, Brasília, DF, v. 31, n. 2, p. 72-79, 2002. Disponível em: <http://www.scielo.br/scielo.php?pid=S010019652002000200008\&script=sci_arttext >. Acesso em:13 out. 2014.

MORENO, N. A. A informação arquivística e o processo de tomada de decisão. Informação \& Sociedade: Estudos, João Pessoa, v.17, n.1, p.9-19, jan./abr. 2007. Disponível em: < http://www.brapci.inf.br/_repositorio/2010/11/pdf_b01b5333e2_0012767.pdf>. Acesso em: 10 out. 2014.

MUELLER, S. P. M. Uma profissão em evolução: profissionais da informação no Brasil sob a ótica de Abbot- proposta de estudo. In: BAPTISTA, S. G.; MUELLER, S. P. M. (Orgs.). Profissional da informação: o espaço de trabalho. Brasília: Thesaurus, 2004. p. 23-54. 
PEREIRA, F.; MACULAN, B. C. M. S.; LIMA, G. Â. B. de O. Monitoria eletrônica e hipertextos: relevância para os profissionais da informação. DataGramaZero, Rio de Janeiro, v. 11, n. 3, p. 6, jun. 2010. Disponível em: <http://www.dgz.org.br/jun10/Art_06.htm>. Acesso em: 14 out. 2014.

PIMENTA, R. M. O futuro do passado: desafios entre a informação e a memória na sociedade digital. In: Sarita Albagli. (Org.). Fronteiras da Ciência da Informação. Brasília: IBICT, 2013, p. 146-171. Disponível em: <http://livroaberto.ibict.br/handle/1/1020 >. Acesso em: 10 out. 2014.

PINHEIRO, L. V. R. Inteligência Competitiva como disciplina da Ciência da Informação e sua trajetória de evolução no Brasil. In: STAREC, C.; GOMES, E.; CHAVES, J. (Org.). Gestão estratégica da informação e Inteligência Competitiva. São Paulo: Saraiva, 2005. p. 17-32.

PONJUÁN DANTE, G. Gestión de información: dimensiones e implementación para eléxito organizacional. Rosário: Nuevo Parhadigma, 2004.

SALES, R. Representação de Domínios em Biblioteconomia e Arquivologia. In: SILVA, F. C.; SALES, R. (Org.). Cenários da organização do conhecimento: linguagens documentárias em cena. Brasília: Thesaurus, 2011. p. 45-70.

SANTOS, P. L. V. A. da C. S. As Novas Tecnologias na Formação do Profissional da Informação. In: VALENTIM, M. P (Org.). Formação do profissional da informação. São Paulo: Polis, 2002. p. 103-116.

SANTOS, V. B. dos. A teoria arquivística a partir de 1898: em busca da consolidação, da reafirmação e da atualização de seus fundamentos. 2011. 279 f. Tese (Doutorado em Ciência da Informação)-Universidade de Brasília, Brasília, DF, 2011. Disponível em: <http://repositorio.unb.br/bitstream/10482/10323/3/2011_VanderleiBatistaSanto s.pdf >. Acesso em: 10 out. de 2014.

SILVA; W. A.; SANTOS, P. K. dos. Gestão de Documentos: uma política arquivística capaz de contribuir com um programa de Inteligência Competitiva. Arquivística.net , Rio de janeiro, v.3, n.2, p. 78-102, jul./dez.2007. Disponível em: <http://www.brapci.ufpr.br/documento.php?dd0=0000005193\&dd1 $=57$ afc $>$. Acesso em: 18 out. 2014.

SILVA, F. C. C. da. Bibliotecários Especialistas: guia de especialidade e recursos informacionais. Brasília: Thesaurus, 2005.

SMIT, J. W.; BARRETO, A. A. Ciência da Informação: base conceitual para a formação do profissional. In: VALENTIM, M.L. (Org.). Formação do profissional da informação. São Paulo: Polis, 2002. p. 9-23.

SOUZA, K. I. de B. M. de. Arquivista, visibilidade profissional: formação, associativismo e mercado de trabalho. Brasília: Starprint, 2011. 
TONINI, R. S. S; SÁ, E. P. O Bibliotecário e a Gestão do Conhecimento. Disponível em: <http://www.sbgc.org.br/sbgc/blog/bibliotecario-e-gestao-doconhecimento>. Acesso em: 20 out. 2014.

VALENTIM, M. L. P. Gestão Documental em Ambientes Empresariais. (Org.). Estudos avançados em Arquivologia. Marília: Oficina Universitária; São Paulo: Cultura Acadêmica, 2012. p. 318. Disponível em: $<$ http://www.marilia.unesp.br/Home/Publicacoes/estudos avancados arquivolo gia.pdf .> Acesso em 19 out. 2014.

VALETIM, M. L. P.et al. O processo de Inteligência Competitiva em organizações. DataGramaZero: Revista de Ciência da Informação, Rio de Janeiro, v. 4 n. 3, p. 1-25, jun. 2003. Disponível em: < http://www.dgz.org.br/jun03/Art_03.htm >. Acesso em: 10 nov. 2014.

VALENTIM, M. L. P. Gestão da informação e Gestão do Conhecimento em ambientes organizacionais: conceitos e compreensões. Tendências da Pesquisa Brasileira em Ciência da Informação, Brasília, DF, v. 1, n. 1, p. 116, 2008. Disponível em: $<$ http://www.brapci.ufpr.br/documento.php?dd0 $=0000007780 \& d d 1=a c c f b>$. Acesso em: 10 nov. 2014.

\title{
VALLS, V. M. O papel do bibliotecário na Gestão do Conhecimento. São
} Paulo: CEDOC, 2008.

\section{Title}

Librarian and archivist: strategic contributions in organizations

\begin{abstract}
Introduction: This research study consists of a theoretical reflection on the performance and activities of information professionals: librarians and archivists. It offers a brief overview of their activities, which are considered strategic in the literature of this field.

Objective: Present the perspectives and possible contributions of the librarian and archivist for the development and implementation of strategic activities of information in organizations.

Methodology: Literature review on the librarian and archivist, its functions and activities in organizations. A theoretical study based on authors of Information Science. Results: The actions taken by librarians and archivists maximize and promote the use of information. With the fundamental concepts and techniques in the area, such as collection and treatment of documents and information, reapply in a new context and valued way. The technical processing of this professional are more strategic than any management activity and necessary in any environment. Professional - Archivist - had greater strategic activity that anyone other professional information.

Conclusions: It concludes that the librarian and archivist have in your profile, training, skills, technical activities (traditional activities), theoretical activities, as well as managerial and strategic activities to be executed within an organization. Its activities and contributions are more than strategic, are also social. Your prospects and possible
\end{abstract}

Inf. Prof., Londrina, v. 5, n. 2, p. 228 - 245, jul./dez. 2016.

http:www.uel.br/revistas/infoprof/ 
contributions are promising and relevant. But also favor the support in decision making, the creation of new knowledge and information processing quality. They have a different role in the Information Management (IM), Knowledge Management (KM), Document Management (DM) and Competitive Intelligence (Cl), as traditionally deals with the technical information and theoretical way.

Keywords:Librarian. Archivist.Practice.Strategy.Organization

\section{Titulo}

Bibliotecario y archivero: contribuciones estratégicas enlas organizaciones

Introducción: Esta investigación presenta una reflexión teórica sobre el rendimiento de los procesos y actividades de los profesionales de la información: bibliotecario y archivero. Establece un breve resumen de sus actividades, considerados estratégicos en la literatura.

Objetivo: Presentar las perspectivas y posibles contribuciones del bibliotecario y archivero para el desarrollo y ejecución de las actividades estratégicas de la información en las organizaciones.

Metodología: Revisión de la literatura sobre el bibliotecario y archivero, sus funciones y actividades en las organizaciones. Un estudio teórico basado en autores de Ciencias de la Información.

Resultados: Las medidas adoptadas por los bibliotecarios y archiveros maximizar y promover el uso de la información. Con los conceptos y técnicas fundamental e sen la zona, como la recogida y el tratamiento de documentos e información, vuelva a aplicar en un nuevo contexto y forma valorada. El proceso técnico de este profesional son más estratégico que cualquier actividad de gestión y necesario en cualquier entorno. Profesional - Archivero - tenido mayor actividad estratégica que cualquier ao transformación profesional.

Conclusiones: Concluye que el bibliotecario y archive retienen en su perfil, formación, habilidades, actividades técnicas (tradicionales), teórico naturaleza, gerencial y estratégico para la organización. Sus actividades y contribuciones son más que estratégica, también son sociales. Sus perspectivas y posibles contribuciones son prometedores y relevante. Pero también favorecer ela póyenla toma de decisiones, la creación de nuevo conocimiento y la calidad de procesamiento de la información. Tienen un papel diferente en los Sistemas de Gestión de Información (GI), Gestión del Conocimiento (KM), Gestión de Documentos (GD) y la Inteligencia Competitiva (IC), que se ocupa tradicionalmente con la información técnica y de forma teórica.

Palabras clave: Bibliotecario. Archivista. El accionamiento. Estrategia. Organización.

Recebido em: 25.08.2016

Aceito em: 30.11.2016 